\title{
O Visconde de São Leopoldo e a fundação dos Cursos Juridicos do Brasil (*)
}

Waldemar Ferreira

A civilização implantou-se, em terras da América, por importação. Não se lançou de semente. Plantou-se de galho ao longo da costa maritima, alcançada, de primeiro, pelos descobridores.

Assim foi, com efeito, nestas paragens admiraveis a que, na frase de Pedro Taques, "a piedade do seu primeiro descobridor pôs o nome de Santa Cruz, e a ambição dos homens converteu depois no de Brasil, pelo interêsse do pau assim chamado" (1).

Repartida a terra nova e virgem, que Pedro Alvares Cabratc descobrira em 1500, mercê da grandeza de el-rei D. JoÃo III, entre beneméritos vassalos, em quatorze capitanias, que êles teriam que abrir, instalar, edificar e povoar, coube a MArtim Afonso de Souza - senhor das vilas de Alcoentre e Tagarro, alcaide-mór do Rio Maior, de heroicas proesas em Ásia, não somente admiradas, como aplaudidas de historiadores do prumo de JoÃo de BARros - a que de São Vicente veio a ser e em que lavrou e ergueu a primeira vila que houve em todo o Brasil, na ilha do santo do mesmo nome. Feito foi êsse acontecido lá pelo ano da graça de 1531.

(*) Disicurso pronunciado na sessão solene de 7 de julho de 1947, em comemoração ao centenário do faleciment do Visconde de S. Leopoldo.

(1) Penro Taques de Almerda Paes leme, História da Capitania de S. Vicente, ed. da Comp. Melhoramentos de São Paulo, pág. 61. 
Logo depois, refere o cronista eximio, que venho seguindo, dentro da mesma ilha, distância de duas léguas por terra, fundou-se a vila do porto de Santos, da qual foi alcaide-mor, e seu primeiro povoador, Braz Cubas, de nome imorredoiro. Escolheu êle, de muita sagacidade, a fim de aliviar trabalho e canseiras a embarcadiços a lavradores, aquêle porto em leiras havidas a Pascoal Fernandes e Domingos Pires, nunca antes habitadas de criaturas tementes a Deús, e nas quais se elevava o outerinho de Santa Catarina, junto ao qual nasceu, ali por 1543 , o povoado de Todos os Santos, que neste substantivo nominalmente se contraiu, mas territorialmente se alargou em moradas modestas e rusticas, em que fogões se acenderam e cruzes se alçaram.

Porto e povoado, aglomerado geográfico e humano erecto sob o patrocinio de Nossa Senhora do Rosário de Santos, tiveram seu destino histórico traçado, assim pelo império das circunstâncias, como pelo poderio dos homens. 'A comprimi-los estava o mar, fonte perene e inexgotavel de seu enriquecimento; e, no fundo da planície alagada, como a emprestar magestade ao panorama, a muralha verde escura, de pincaros azulados, da serrania da Paranapiacaba, a desafiar a audacia intemerosa dos que haveriam, logo mais adiante, de prolongar, no planalto misterioso, a arremetida dos navegadores, porfiando, como no verso camoneano, "a ver os berços onde nasce o dia"

Ponto de contacto da capitania são vicenteana com o mundo exterior; receptáculo de homens, de mercadorias e de idéias transmigrados do velho mundo - converteu-se Santos no empório movimentado pelo intercâmbio intermitente, que oscilava com as chegadas e com as partidas das caravelas que não mais ostentavam, em seus panos, a cruz da Ordem de Cristo, mas a corôa real da bandeira portuguêsa.

O burgo tímido dos primeiros tempos começou de desenvolver-se, vindo a adquirir fóros de cidade, em que sobressaía, ao lado de suas igrejas, a primeira santa casa de misericordia brasileira. Lento foi o seu progresso, a 
despeito de tudo. Mais não tinha, decorridos dois séculos, do que treze ruas, travessas, bêcos e vielas. Eram aquelas, pelo censo de 1765, examinado por Alberto Souza, a Direita, que era a principal, com setenta casas, lado a lado. Começava nos Quatro Cantos e terminava no Convento do Carmo. A atual Frei Gaspar também nos Quatro Cantos principiava e ia dar na Alfândega. Seis casas de lado a lado. O Bêco da Alfândega Velha. A rua da Praia. A rua de São Francisco. O bêco de Maria Francisca. O bêco de Gonçalo Borges. A travessa do Parto. A travessa do Carmo. A rua que principiava no Pelourinho e ia dar em Santa Catarina. 'A rua Pequena. A que saía do canto do Hospital e chegava até ao fim dos Quartéis. A dos Cortumes, que ia do caminho da fonte de São Jerónimo até ao Valongo (2).

Desdobradas ao longo do pôrto ou indo nêle desembocar, essas ruas estreitas, que ainda conservam os seus traçados, a despeito das edificações que as ladeiam, assobradadas quase todas e algumas substituidas por edificios de cimento armado de quatro ou mais andares, eram as arterias por que se comunicavam gentes afeitas ao trabalho e que serviam de intermediários entre o mundo exterior e o sertão, que no planalto se estendia. Era o burgo comercial por excelência, de onde haviam já partido para a glória duas figuras eminentissimas, oriundas do mesmo leito - o Padre Bartolomeu Lourenço de Gusmão, o Padre Voador, o primeiro que singrou os ares, com a sua aéronave, em fórma de pássaro e que Passarola se chamou; com a qual, partindo do Castelo de São Jorge, poisou no terreiro do Paço, em Lisboa, em abril de 1709; e seu irmão Alexandre de Gusmão, cujo gênio politico se sagrou no tratado de Madrid, de 13 de janeiro de 1750, por via do qual o insigne homem de Estado, consolidando a obra de conquista territorial das bandeiras paulistas, traçou, como

(2) Azberto Souza, Os Andradas, Tip. Piratininga, vol. I (São Paulo, 1922), pág. 151. 
Rodrigo Otavio o disse, a carta politica da América Latina (3).

Entre os comerciantes, a êsse tempo estabelecidos em Santos, se encontrava José Fernandes Martins, originário da vila de Guimarães, em Portugal. Esse minhôto, cuja familia tinha o seu solar na Quinta do Couto ou de Capilhães, na freguesia de Nossa Senhora de Oliveira, daquela velha cidadé portuguêsa, contraiu núpcias com D. Teresa DE Jesus Pinheiro, filha do capitão José de Almeida Soares, que foĩ casado com D. Mariana Ribeiro de Andrada. Entroncou-se na familia dos Andradas, de tanto renome ao tempo, e que se inscreveu na história do Brasil com brilho inexcedivel.

De seu consórcio com a santista ilustre, teve o comerciante lusitano um filho - José Feliciano Fernandes PrNHEIRo, nascido aos 9 de maio de 1774. Tratou, como era natural de dar-lhe educação condigna da familia a que pertencia, pelo costado materno. A falta de escolas e de professores contribuiu para que o menino aprendesse a ler com os caixeiros, assim se chamavam os comerciários de hoje, da casa comercial de seu pai, e sob as vistas dêste. E que tinham sido expulsos os mestres jesuitas de toda a colonia, impelidos pela politica férrea do MARQUez DE POMBaL. Mais adiantado, iniciou-se, com seus dois irmãos, no estudo da gramática latina, com o mestre Joño Floriano, e nêle não foi muito feliz, êle mesmo o disse. Andou "mendigando lições, até que um velho carmelita, o reverendo padre mestre VIDELA, admitindo ao ensino dois sobrinhos seus, consentiu tambem benignamente receber-me para êsse fim, prestando-nos a todos êste serviço, só por bem fazer". Assim foi até chegar, despachado pela Mêsa Censória de Lisboa, o professor régio, José Luiz dE Morais Castro, natural da cidade do Pôrto. Com êle se tornou provecto na língua latina. Com o clérigo José XAvier dE Toledo apren-

(3) Rodrigo OtÁvio, Alexandre de Gusmẩo et le sentiment américain dans la politique internationale, ed. Sirey (Paris, 1930). pág. 16. 
deu francês, o que causou espanto a um tio, cônego da catedral de São Paulo, assustado com que o sobrinho estivesse a entrar nos segredos da lingua de Voltaire; e nêsses estudos teve José Feliciano Fernandes Pinheiro como colega ao seu parente Antonio Carlos de Andrade e Sulva.

Preparava-se para vir estudar Filosofia Racional e Moral nesta cidade de São Paulo, da qual havia cadeira pública regida pelo Padre RoQue, quando se deu a interferência do Cônego José Xitvier de Toledo para que seu pai o fizesse seguir para a Universidade de Coimbra.

$\mathrm{Na}$ velha e célebre universidade portuguêsa, vencendo dificuldades de todo o estilo, concluidos os preparatórios, êle, em outubro de 1793, se matriculou no Curso Jurídico. Como, porém, sua familia o destinara à vida eclesiástica, matriculou-se, também, na Faculdade de Direito Canônico, cujo gráu tomou em 25 de junho de 1798, com as formalidades da lei. 0 falecimento de sua mãe, porém, levou-o. com o assentimento do pai, a preferir a carreira da magistratura, para a qual se achava igualmente apto, graças ao método de simultâneo estudo de ambos os direitos, seguido na Universidade de Coimbra.

Pretendeu José Feliciano, bacharel formado, deixar-se ficar em Portugal, a fim de tentar carreira; mas encontrou fechadas todas as portas a que bateu. Frustradas várias tentativas, um dia encontrou-se com Antonio Ciarlos dE Andrada E Silva, igualmente desempregado. Recebera êste de MANuel Jacinto da Gama proposta para entrar para estabelecimento literário e tipográfico que, junto a Arrôios, no sitio do Arco do Cego, em uma Quinta de Manique, se ia instalar sob a imediata proteção de D. RonRigo de Souza Coutinho, Ministro e Secretário de Estado de Ultramar, e que seria dirigido pelo mineiro Padre Manuel Francisco José Mariano da Conceição Veloso, religioso capucho do Rio de Janeiro, sábio naturalista e pensionista do Estado. Oferecia-lhe o seu patricio santista ensejo de trabalho, que aceitou, percebendo, como remuneração, cama e mesa, além de muita esperança. Esmeraram-se os dois santistas, nêsse 
trabalho conjunto, aprimorando sua cultura. Antonio CARLos levado para os estudos filosóficos e publicísticos; e JosÉ Feliciano dedicado a assuntos históricos e econômicos.

Impôs-se êste, por sua inteligência e cultura ao ministro. D. Rodrigo de Souza Coutinho, graças sobretudo à interferência de seu parente Drogo de Toledo Lara e Ordonhes que lhe gozava da privança. Mais feliz que os da "grande turba de bachareis requerentes" que então existia em Lisboa, foi, afinal, por aquêle ministro despachado "para criar uma alfândega nas colonias do Rio Grande do Sul e Ilha de Santa Catarina com Mercê e Serventia Vitalicia do juiz dela, por decreto de 15 de julho de 1800"; e, para assegurar sua subsistência, enquanto a alfândega se não criasse, o decreto de 1 de junho de 1801 nomeou-o auditor de todos os regimentos da capitania do Rio Grande, de que se lhe passou patente, sendo, ademais, e em atenção aos serviços, que ia fazer, por decreto de 7 de junho de 1801, condecorado com o Hábito de Cristo.

Antes que aquêle ano se findasse, regressou José FeLTciano Fernandes Pinheiro ao Brasil. Permaneceu no Ric de Janeiro o tempo necessário para a tomada das providências que lhe permitissem instalar a repartição fazendária em que teria de exercer as funções de seu cargo. Transportou-se, em meados de 1804, para o Rio Grande. do Sul. Os esforços, que então desenvolveu, para superar as dificuldades e tropeços que se lhe antepuseram, foram imensos. Os negociantes da capitania, sentindo que os lucros do contrabando, até hoje não de todo supressos, seriam diminuidos, hostilizaram-no. Só depois que ali chegou ogovernador PAUlo dA GAMA, com ordens para fundar a Junta Real da Administração da Fazenda Pública, foi que esta se organizou, tendo como deputado, servindo de tesoureiro, procurador da Corôa e Fiscal da Fazenda, aquêle funcionário. Instalou-se a Junta em 1804. No entretempo, como auditor de Marinha, Fernandes Pinheiro serviu na. esquadra de Campbell. Promovido a coronel em 1811, reuniu-se, em 1812, ao exercito pacificador nas imediações de: 
Montevidéu. Participou da comissăo militar julgadora dos: implicados na campanha cisplatina.

Espírito afeito aos estudos históricos, pôs-se a examinar documentos e a interpretar os fatos politicos, administra-tivos e sociais da capitania, em que a sua vida se desen-volveria longamente e na qual, por fim, descansaria para todo o sempre. Nela deitou raizes de sangue e de afetos. consorciando-se com D. Maria Elisa Lima, neta do primeiro Visconde de Pelotas. Ligou-se a antigas familias da terra, em que avultavam figuras de generais e de politicos. Teve prole e descendência. Dos seus labores de historiador resultaram - os Anais da Capitania de São Pedro,. cujo primeiro volume editou a Imprensa Régia, do Ria. de Janeiro, em 1819.

Com tudo isso, teceu o trabalhador os florões de sew: renome, que se expandiu pelo país e repercutiu na sua capitania natal. Esta preparava o movimento libertador." aacional, sofregamente. Conspirava-se às claras. O espirito autonomista repontava nas deliberações das câmaras municipais. Em todas as almas acendia inquietações. A visão de estardista de José Ponifácio de Andrada E Silva abria as diretrizes dos acontecimentos, que se precipitavam, aquém e além mar. Triunfara em Lisbôa a revolução libe-ral de 1820, deflagrada no Pôrto. Instaladas as Côrtes, de- veriam compartir de seus trabalhos representantes do Brasil e a provincia de São Paulo teriam que escolher os seus na altura do cometimento. Reuniu-se a Junta Eleitoral em C. de agosto de 1821, na Casa do Conselho. Instalou-a o presidente do Govêrno Provisório, João Carlos Augusto d’OeyNHAUSEN, elegendo-se presidente dos trabalhos José Boni-Facio, nume tutelar, figura maior do tempo que se foi e nunca mais sobrepujada. Saíram eleitos Antonio Carlos Ribeiro de Andrada; José Rrcardo da Costa 'Aguiar, que exercia o cargo de ouvidor da comarca de Marajós, na provincia do Pará; e José Feliciano Fernandes Pinheiro, juiz da Alfândega de Porto Alegre. Três santistas. Nicolaư 
Pereira de Campos Vergueiro, português de origem.Franasco de Paula Souza e Melo, ituâno. E o Padre Diogo ANTonio Feisó, natural da cidade de São Paulo. Dêsses, não wexercu o mandato, por doente, Paula Souza. Elegeram-se mais dois suplentes, Antonio Manoel da Silva Bueno e Antonio Pais de Barros, ituâno, o primeiro Barão de PiraAcicaba.

Ao que se afirma, posto contestado por Alberto Souza, teria sido José Feliciano Fernandes Pinheiro eleito pelas rduas provincias - a de seu domicilio e a de seu nascimento, tendo optado pelo mandato dos paulistas, que buscaram distingui-lo pelos seus altos meritos, comprovados por sua eleição, achando-se fóra de São Paulo desde que se partiu para os seus estudos em Coimbra.

A primeira e última representação brasileira às Côrtes ande Lisboa bem exprimiu o vigor da terra e da gente. Ne"nhuma, no conceito de Otavio Tarquinio de Sovza, sobrepujava, entretanto, a de São Paulo, com Antonio Carlos, o sorador máximo do seu tempo, Vergueiro, uma das figuras. politicas brasileira de maior complexidade, Fernandes Pinherro e Feisó (4). Era, no dizer do historiador, "repressentação ilustre, que resguardaria com denodo o pundonor brasileiro, seria a mais altiva e corajosa, mas não conse:guiria impedir o inevitavel”. No fragôr dos debates, e "quando a representação brasileira era atacada no recinto das Côrtes e nas ruas de Lisboa, Fernandes Pinheiro, em : sessão, declarou que não assinaria a Constituição, que estava .a votar-se, "por estar em manifesta contradição com a vontade de sua provincia”. 'Apoiaram-no, na sessão seguinte, -Antonio Carlos, Silva Bueno e Costa Aguiar; e, em carta dirigida às Côrtes, Feisó declarou que só juraria a Constituição "obrigado, violentado e arrastado". Para cumprir $\because$ seu proposito, sete representantes brasileiros preferiram

(4) Otánio Tarquínio de Souza, Diogo Antônio Feijó, ed José : Dlimpio, Rio, pág. 41. 
Tugir de Lisboa, seguindo para a Inglaterra sem passaportes e sem licença das Côrtes. Quatro paulistas, três baiânos. antonio Carlos, Silva Bueno, Drogo Feijó, Costa Aguiar, Cipriano Barata, lino Coutinho e Francisco Agostinho Gomes. Dos que permaneceram em Lisboa, deixaram de assiná-la Vergueiro, Muniz Tavares, José Joaquim de Faria ve José Maria de Souza Almeida. Assinaram-na os demais, entre êles Fernandes Pinheiro, que voltou atrás, a instâncias de seu amigo, o deputado português Trugoso. Assinou-a, êle o disse em suas memórias, "sacrificando-me, e acalmando a colera, que contra nós se exasperava". Quando isso aconteceu, e foi em 25 de setembro de 1822, dezoito dias haviam decorrido após ao em que, em terras de São Paulo de Piratininga, o Principe Regente, impelido pelas circunstâncias que José Bonifacro de Andrada e Silva de certo modo havia conduzido ao seu desfecho historico, rompera os laços politicos que uniam Brasil a Portugal. Muitos sóis ainda haveriam de nascer e de pôr-se, tonalizando os ânimos que, em Lisboa, tanto se haviam exaltado contra os representantes da representação brasileira e, principalmen te, contra a paulista, até que lá chegasse a noticia, que hoje, com a fulminância de raio, teria sacudido a nobre ggente lusitâna, de que provimos.

Continuou, pois, Fernandes Pinheiro no exercicio do mandato, verdadeiramente putativo e prorrogado para as Côrtes Ordinárias, instaladas em 1 de dezembro e a que evitara de comparecer, êle o disse, para "não autorizar, com minha presença, discussões menos decorosas, como a relạtiva à Rainha, e outras semelhantes" Já havia sido recebido pela Alcademia das Ciências de Lisboa, de que era vice-secretário o brasileiro Francisco Vilela Barbosa, em sessão em que se dera conta do relatório da comissão por ela encarregada de ajuizar do merecimento dos Anais da Provincia de São Peáro, cujo segundo volume naquêle ano saira dos prelos da Imprensa Nacional. 
Tanto que, nos primeiros dias de 1824, a noticia da independência do Brasil chegara a Lisbøa, tratou o deputado brasileiro de mandato extinto de retornar ao Brasil; e preparava suas malas e partidas quando os estudantes brasileiros da Universidade de Coimbra o procuraram, atribuindo-lhe o incumbência de promover a criação do ensino superior no Brasil.

Quando, em 30 de março de 1823, a bordo do navio Três Corações, deixou o porto de Lisboa, já se achava Fernandes Pinheiro eleito deputado à Assembléia Geral Constituinte pelas provincias de São Paulo e de São Pedro do Rio Grande do Sul. Chegado ao Rio, sofreu, naturalmente, os embates da agitação politica, por haver assinado a Constituição de Portugal. Envolveu-se em polêmicas, defendendo sua atitude. Disso resultaram divergências com os Andradas, que o levaram a tomar assento, aos 24 de maio, na Assembléia, que se instalara em 3, como representante da provincia do extremo sul.

Entrando a compartir dos trabalhos daquele augusto. e histórico parlamento, composto de 26 bachareis em direito e cânones, 22 desembargadores, 19 créligos entre os quais um bispo, e 7 militares, entre os quais 3 marechais: de campo e 2 brigadeiros (5), o paulista da bancada gaúcha desenvolveu intensa atividade, à altura de seus notaveis méritos. Relatou o parecer da comissão que examinou os artigos adicionais do projeto da Constituição do Brasil, lido pelo deputado Antonio Carlos Ribeiro de Andrado Machado e Silva. Tendo a Assembléia função legislativa ordinária, vários projetos de lei, entre os quais se sobreleva o apresentado em sessão de 14 de junho de 1823, criando, no Império, uma universidade, "para assento da qual devia ser preferida a cidade de São Paulo, pelas vantagens naturais e razões de conveniência geral" Atendeu, pois, ao apelo dos estudantes brasileiros de Coimbra, lançando duas:

(5) F. I Marcondes Homem de Melo, A Constituinte perante a História, ed. Tip. Atualidade (Rio de Janeiro, 1863), pág. 4. 
asserções celebres, no sentir de um de seus biografos. Primeiramente, notou êste, "impunha o ensino da economia politica e do direito público, isto é, o ensino das ciências politicas e sociais que levariam a modificar o titulo da Escola de Direito para Escola de Ciências Juridicas e Sociais, - que importava na novidade de se professarem duas disciplinas que em França se ensinaram nas Universidades somente em mil oitocentos e muitos. Em segundo lugar, Fernandes Pinheiro proclamou quase a desnecessidade do ensino do direito romano", posto não fôsse êle: senão o Visconde de Cairú a dar ao asserto "expressão consideravel" (6).

(6) FeiJó Bittencourt, Instituto Histórico. Os fundadores. Ed. Imprensa Nacional (Rio de Janeiro, 1938), pág. 80.

- o discurso do futuro Visconde de São Leopoldo, na Assembléia Constituinte, foi êste:

"As disposições e eficácia desta assembléia sôbre o importantissimo ramo da instrução pública, não deixam duvidar de que essa base sólida de um Govêrno Constitucional ha de ser lançada em nosso código sagrado de uma maneira digna das luzes do tempo e da sabedoria de seus colaboradores. Todavia, esta conviç̧ão, e ao longe as melhores esperanças, nem por isso devem acanhar de submeter já à consideração desta assembléia uma indicação de alta monta, e que parece urgir. Uma porção escolhida da grande familia brasileira, a quem um nobre estímulo levou à Universidade de Coimbra, geme ali debaixo dos mais duros tratamentos e opressões, não se decidindo, antes de tudo, a interromper e a abandonar sua carreira, já incertos de como será semelhante conduta avaliada por seus pais, já desanimados por não haver ainda no Brasil institutos, onde prossigam e rematem seus encetados estudos. Nessa amarga conjuntura, voltados sempre para a Pátria, por quem suspiram, lembraram-se de constituir-me com uma carta que aqui apresento; correspondendo, pois, guanto em mim cabe, a tão lisongeira confiança, e usando ao mesmo tempo das faculdades que me permite o art. $6 .^{\circ}$ do nosso regimento interno, ofereço a seguinte

INDICAÇÃ̃O

"Proponho que no Império do Brasil se crie, quanto antes, uma Universidade pelo menos, para assento da qual parece dever ser pre- 
Alcançou o projeto parecer favoravel da Comissão de. Instrução. Redigiu-o Martim Francisco Ribeiro de AndraDA E Silva. Criar-se-iam duas Universidades. Uma em São Paulo. Outra em Olinda. Teriam por escôpo o ensino de: todas as ciências e belas letras. Haveria, e desde logo, "um" curso jurídico na cidade de São Paulo, para o qual o govêrno convocaria mestres idôneos, os quais se governariam provisoriamente pelos estatutos da Universidade de Coim-bra, com aquelas alterações e mudanças que êles, em mesa

ferida a cidade de S. Paulo, pelas vantagens naturais e razões de economia geral. Que na Faculdade de direito civil, que será sem: dúvida uma das que comporá a nova Universidade, em vez de multiplicadas cadeiras de direito romano, se substituam duas, uma de direito público constitucional, outra de economia politica.

"Paço da Assembléia, 12 de junho de 1823. - Fernandes Pi"NHEIRO."

E o parecer da Comissão de Instrução Pública consistia nêsteprojeto:

"A Assembléia Geral Constituinte e Legislativa do Brasil decreta :-

1. - Haverá duas Universidades, uma na cidade de São Paulo. e outra na de Olinda, nas quais se ensinará todas as ciências e belas-letras;

2. ${ }^{\circ}$ - Estatutos próprios regularão o número e ordenados dos. professores, a ordem e arranjamento dos estudos;

$3 .^{\circ}$ - Em tempo oportuno se designarão os fundos precisos a ambos os estabelecimentos;

4. - Entretanto haverá desde já um curso juridico na cidade. de São Paulo, para o qual o Govêrno convocará mestres idôneos;. as quais se governarão provisoriamente pelos estatutos da Universidade de Coimbra, com as alterações e mudanças, que, em mesa presidida pelo vice-reitor, julgarem adequadas às circunstâncias e luzes: do século;

5. - S. M. o Imperador escolherá dentre os mestres um parar servir interinamente de vice-reitor.

Paço da Assembléia, 19 de agosto de 1823. - Martim Franciscom Ribeiro de Andrada. - Antonto Rodrigues Veloso de Oliverra. 'Antonio Gonçalves Gomide. - Manoel Jacinto Nogueira da Gama". 
presidida pelo vice-reitor, julgassem adequadas às circuns-tâncias e luzes do século".

Veementemente combatido, sobretudo porque a cidadede São Paulo era assaz modesta e desprovida de tudo e an falar dos paulistas, cantado e sêco, modulado de apócopes, não mui correto - veiu a termo. Aprovou-se. Sancionouse. Faltou-lhe, porém, a promulgação imperial, denega-da a outros projetos por efeito do golpe de Estado que em 12 de novembro de 1824, dissolveu a primeira Assem-. bléia Constituinte Brasileira.

Teve o gesto o aplauso de Euclides dA Cunht. $A$ in ${ }_{-1}$ tervenção monárquica foi, para êle, "decisiva, oportuna e: benéfica". Justificou o conceito, asseverando que "uma constituição, sendo uma resultante historica de componen-.tes seculares, acumuladas no evolver das idéias e dos cos-tumes, é sempre um passo para o futuro garantido pela energia conservadora do passado. Tradicional e relativa, despontando de leis que se não fazem, senão que se descobrem, no conciliar novas aspirações e necessidades com os. esforços das gerações anteriores, é um traço de aliança na. solidariedade dos povos. E nós iamos partí-lo" (7).

Partimô-lo, a despeito de tudo, por isso que o Imperador teve que render-se ao império da consciência nacional; e dos despojos da Assembléia Geral Constituinte, dissolvida por "haver perjurado ao tão solêne juramento, que prestou à Nação, de defender a Integridade do Império, sua Independência e minha Dinastia", teve que recolher a. material com que se elaborou, em Conselho de Estado, a Constituição Politica do Império do Brasil, que êle promulgou aos 25 de março de 1824 .

Poucos dias antes, em 8 de março, havia JosÉ Feliciano Fernandes Pinheiro assumido o govêrno da provincia do Rio Grande do Sul, para que fora nomeado em 25 de no-

(7) Euclides da Cunha, A Margem da História, ed. Chardron (Porto, 1909), pág. 289. 
"vembro de 1823. Não é êste o momento para fazer o estudo apologético de sua brilhantissima governança. Saliente-se, todavia, que fundou a colonia e depois cidade de São Leopoldo, cujo nome se inscreveria, não muito depois, no título com que se galardoou e com que passaria para a historia - o de Visconde de São Leopoldo.

Trabalhoso lhe foi_o seu biênio governamental. Lutas politicas. Lutas militares. Realizações inúmeras na ordem administrativa. Mas tudo isso o recomendou à estima pública, de molde a elevá-lo ao govêrno imperial. Nomeado Ministro e Secretário de Estado dos Negócios do Império, passou o govêrno da provincia de São Pedro do Rio Grande do Sul ao Brigadeiro José Egidio Gordilho. Transferiu-se para o Rio de Janeiro. Empossado na pasta, interinamente - ocupada pelo Visconde de Caravelas, ainda mereceu a graça imperial que lhe deu o titulo de Conselho e o escolheu senador pela provincia de São Paulo. Serviu de plenipotenciário para negociar tratados de amizade, comércio e nàvegação com a Grã Bretanha e a Prussia. Ocupando, interinamente, o Ministerio de Estado dos Negócios da Justiça, instalou o Poder Legislativo. Instalando-o, tratou de revi- ver o projeto, que à Assembléia Geral Constituinte apresentara, criando os cursos juridicos no Brasil. Medida governamental havia já sido tomada, mas infrutiferamente, pelo decreto ds 9 de janeiro de 1825, mandando instalar um, provisoriameute, na cidade do Rio de Janeiro, com as convenientes cadeiras e letras, e com o método, formalidades rexulamentos e instruções que baixasse o conselheiro :Estevam Ribeiro de Rezende, Ministro e Secretário de Estado dos Negócios do Império, depois Marquês de Valença.

Graçrs aos esforços de Fernandes Pinheiro, submeteu a Comissão de Instrução Pública à Câmara dos Deputados, em sessão de 5 de julho de 1826, proposta criadora de curso jurídico no Rio de Janeiro. Emenda substitutiva de Paula SouzA, deputado paulista, mandou que dois fossem, um em .São Paulo, outro em Olinda. Provocou esta emenda as 
mesmas oposições que se haviam formulado na Assembléia Geral Constituinte contra a preferência a São Paulo. Destacou-se, desta vez, entre os opositores, Bernardo Pereira de Vasconcelos, que antes mesmo de promulgado o projeto, em agosto de 1827, no entanto, pediria que Sua Majestade Imperial o nomeasse lente proprietário de qualquer cadeira daquele Curso Juridico, não se recusando "a qualquer exame", que necessario fôsse. E, nos debates, excedeu-se, fazendo a mais severa critica ao sistema de ensino da Universidade de Coimbra. Responderam ao deputado mineiro o espirito-santense Batista Pereira e o paulista Campos Vergueiro, que viria a ser o quarto diretor do que se instalaria em São Paulo. Veiu o projeto a aprovar-se, em terceiro turno, na sessão de 31 de agosto de 1826. Remetido ao Senado, no ano seguinte, pouco ali se discutiu. Converteu-se na lei de 11 de agosto de 1827, referendada pelo Ministro do Império, José Feliciano Fernandes Pinheiro. Estava em vias de realizar-se o seu grande proposito. Deu de si tudo quanto foi possivel, de molde a vencer as naturais dificuldades do empreendimento. Coube-lhe nomear, por decreto de 13 de outubro de 1827, o primeiro diretor e o primeiro lente do Curso Juridico de São Paulo - o Tenente General José Arouche de Toledo Rendon e o Dr. José Maria de Avelar Brotero, ambos doutorados em leis pela Universidade de Coimbra.

Não permaneceu por muito tempo o Visconde de São Leopoldo no govêrno. Demitiu-se logo depois, em 20 de novembro de 1827, quando D. Pedro I constituiu o primeiro gabinete parlamentar, organizado por Pedro de Araujo Lima, que viria a ser o Marquês de Olinda. Se continuou no Conselho de Estado, perdeu as graças de Sua Majestade Imperial. Retornou aos seus pagos das cochilhas rio grandenses do sul. Regressou à Côrte. Fundou o Instituto Histórico e Geográfico. Conheceu o ostracismo. Permaneceu no Senado. Alquebrado, definitivamente se instalou em Porto Alegre, onde se finou aos 6 de julho de 1847. 
Comemorando o primeiro centenário do desaparecimento do Visconde de São Leopoldo da vida terrena, a Congregação dos Professores da Faculdade de Direito da Universidade de São Paulo homenagêia a memória do seu criador. Enaltece-lhe o cometimento. Bendiz o seu nobre esforço, no sentído de dar raizes nacionais à cultura jurídica brasileira.

Fiel às instruções reservadas, que em 5 de janeiro de 1785 ministrou aos governadores das capitanias do Brasil, no sentido de contê-lo em regime de brasa apagada, por isso que, sendo "o país mais fertil e abundante do mundo em frutos e produções da terra", se a tais vantagens se reunissem "as da industria e das artes, para o vestuário, luxo e outras comodidades, ficariam os mesmos habitantes totalmente independentes da metropole", motivo por que era "de absoluta necessidade acabar com todas as fábricas e manufaturas do Brasil"; seguindo essa politica, Portugal nunca pensou em fundar uma Universidade na sua colonia americana, como, salvo engano, até hoje ainda não o fez em suas colonias de Asia e Africa.

Diferentemente agiu a Espanha. Pelo descobrimento da América, embebidos do espirito de humanismo, que celebrava com as suas vitorias, os espanhóis, salientou-o STEPhen D'Irsay, não perderam o ensejo de juntar à espada dos seus conquistadores, a cruz dos seus missionarios e o livro dos seus mestres. A civilização européia, pela primeira vez, transpôs os mares. Três anos após à conquista do México, em 1525, ocorreu ao franciscano ZumatRAGA e ao vice-rei Mendoza ali fundar a primeira universidade. Concedida a outorga por carta de fundaçã̀o de 1551, confirmada, mais tarde, por FeuIPE II, ela abriu suas portas em 1553, com as três faculdades usuais, às quais se juntou a de medicina. Recebeu a Universidade do México os mesmos privilégios que sua irmã mais velha, a de Salamanca, largamente dotada pelo govêrno real. Entraram os jesuitas a ensinar filosofia em 1570. A sua biblioteca foi 
a maior da América Latina. Chegou a ter quinhentos alunos. Teve que enfrentar as vicissitudes do país. Suspensa e suprimida muitas vezes, ela subsiste ainda como centro de alto ensino nacional.

Igualmente aconteceu no Perú, conquistado, em 1532, por Pizarro. Atendendo às solicitações do dominicano Thomas de San Martin e da municipalidade da Ciudad de los Reyes, outorgou CArlos Quinto os privilégios habituais, segundo o modelo de Salamanca, para a universidade que lá se erigisse, criando-se, em 1551, a Universidade de São Marcos, que ainda hoje se ostenta em Lima, vetusta e nobre, instalada no convento dominicano, e sua ereção foi confirmda pelo papa Pıo V. Universidade efêmera teve a ilha de São Domingos em 1538. Projetou-se a de Santiago do Chile em 1602. Coube a um frade Fernando Trejo, nascido em terras de Santa Catarina, no Brasil, fundar, em 1613, a Universidade Nacional de Córdoba, na República Argentina. Tentou-se, em 1623, fundar uma universidade dominicana em Bogotá, na Colômbia (8).

Ha mais de duzentos anos funciona a Universidade de Havana, em Cuba.

Só em 1790, mercê do movimento da Inconfidência Mineira, e entrava nos planos dos estudantes brasileiros da Universidade de Coimbra, que ali o esboçaram, no Brasil se sonhou com uma Universidade, em Vila Rica.

Não permitiram as condiçôes da colonia portuguêsa da 'América que, mesmo depois de proclamada a independência, no Brasil se fundasse uma Universidade. Mais não tivemos do que os colégios dos jesuitas e mestres avulsos de primeiras letras e de filosofia e retórica e de linguas patria, latina e francêsa. Só com a chegada de D. JoÃo VI se fundaram, em 1808, as escolas médicas da Bahia e do Rio

(8) STEPHEN D'IRSAY, Histoire des Universités Françaises et Etrangéres, ed. Auguste Picard, vol. II (Paris, 1935), pag. 7. 
de Janeiro. Instalou-se a primeira aula de economia politica, bem como a primeira de comércio.

Coube, pois, ao Visconde de São Leopoldo concretizar o sonho de quantos moços brasileiros foram estudar em Coimbra a ciência juridica, criando os Cursos Juridicos que, se instalaram em 1 de março de 1828, em São Paulo; e a 15 do mesmo mês e ano, em Olinda.

A primeira Universidade somente se criaria no Rio de Janeiro pelo decr. n. 14.343, de 7 de setembro de 1920, promulgado pelo presidente Epitácio Pessoa; e a de São Paulo pelo decr. n. 6.283, de 25 de janeiro de 1934, que imortalizou o nome de Armando de Salles Oliveira.

Há 119 anos que, nesta casa, se ensina o direito. Por igual tempo se homenagêia o nome de José Feliciano FerNAndes Pinheiro, o Visconde de São Leopoldo, que ainda hoje comemoramos, no centenário de seu falecimento. 0 serviço, que êle prestou ao Brasil, é dos que jamais se encarecem demasiadamente. Basta que se examine o panorama da cultura juridica, que êle propiciou e teve os mais largos e profundos reflexos em toda a América de linguas latinas. Assim foi com o código criminal de 1830, que serviu de base para o espanhol de 1848. Aquêle "codigo brasileño fué, a su ver", disse-o, ainda agora, JIMENEz DE AsuA, "inspirador del Código español de 1848" (9). De torna viagem, através dêste, a sua influência foi sensivel nas legislações latino americanas, a despeito do seu sentido nacional e próprio.

O código de comércio de 1850 , por seu turno, repercutiı vastamente nas leis mercantis sul-americanas, sendo sensivel a sua influência no argentino de 1857 e nos que nêle se abeberaram.

(9) Luiz Jimenez de AsuA, Códigos Penales Internacionales segun. los textos oficiales, Editorial Andrés Bello (Caracas, 1946), vol. 1, pág. 151. 
Póde-se dizer, por certo, que nesses códigos agiu a cultura portuguêsa, recebida em Coimbra pelos juristas, que os elaboraram e redigiram. Ainda não haviam surgido no cenário juridico brasileiro os formados pelos cursos juridicos de Olinda e de São Paulo. De uma e de outra, entretanto, surgiu o gênio de Augusto Teixeira de Freitas, que foi realmente co-autor do projeto de código civil da Argentina, elaborado pelo grande Dalmacio Vélez Sarsfield, como êste mesmo proclamou, sem se sentir diminuido, antes engrandecido, por se haver servido dos trabalhos de um jurisconsulto, "sólo comparables con los de SAvignY" (10).

Sejam êsses e outros grandes resultados alcançados pelos cursos juridicos, que o Visconde de São Leopoldo criou, em 1827, o premio do seu nobre esforço e a consagração definitiva de seu grande nome, sempre pronunciado com veneração e com respeito.

(10) Enrreue Martinez Paz, Freitas y su influencia sobre el Código Civil Argentino, Imprenta de la Universidad (Cordoba, 1927), pág. LVI. 